\title{
The Q-tube System, A Nonconventional Technology for Green Chemistry Practitioners
}

Francesca Giulia Nacca ${ }^{1}$, Orsola Merlino ${ }^{1}$, Francesca Mangiavacchi ${ }^{1}$, Dorota Krasowska ${ }^{2}$, Claudio Santi ${ }^{1}$ and Luca Sancineto ${ }^{1,2, *}$

${ }^{I}$ Department of Pharmaceutical Sciences, Group of Catalysis and Green Chemistry - University of Perugia, Via del Liceo 1 - 06100 Perugia, Italy; ${ }^{2}$ Centre of Molecular and Macromolecular Studies, Polish Academy of Science, Sienkiewicza 112 90-363 Łódź, Poland

\begin{abstract}
Background: High-pressure chemistry offers the possibility to have faster and cleaner transformations thus addressing most of the green chemistry principles. Among the devices recently developed, Q-tube is worth mentioning since it is cheap, easy to handle, safe and highly versatile.

Methods: The most recent and interesting results obtained using such technique are reviewed in this study.

Results: Examples of the Q-tube assisted reactions in organic synthesis are presented in a critical manner making where possible, a comparison with conventional heating strategies and unconventional energy source such as microwave or ultrasounds assisted synthesis. The application of Q-tube pressure reactor in biofuels manufacture is also discussed.
\end{abstract}

A R T I C L E H I S T O R Y

Received: July 09, 2017
Revised: August 25, 2017
Accepted: August 28, 2017
DOI:
10.2174/2213346104666170908160741

Conclusion: The literature survey clearly revealed that Q-tube is a valid tool in organic synthesis.

Keywords: Q-tube, high pressure, multicomponent reactions, green chemistry, microwave, ultrasounds, biofuels.

\section{INTRODUCTION}

In the course of our studies on the development of new green procedures in organic synthesis [1-3], we came across the device named Q-tube, recently. As usual, before starting the experimental work, we performed a deep literature analysis that culminates in this mini-review. This manuscript is not directed to specialists but rather for someone interested in becoming better acquainted with details and application of this innovative device.

Starting from 1981, when the Isaacs seminal book on High Pressure Chemistry (HPC) was published [4], several examples were reported in literature [5-7]. HPC allows to obtain faster and cleaner transformation by simply modifying some physical properties of solvents, reagents and final products. For liquids, the properties that are mostly modified are: boiling point, viscosity, density and dielectric constant, and in the case of protic media such as water, also the ion product constant is modified once the pressure changes [8]. The main advantage of carrying out a reaction under pressure is the possibility to overcome the boiling point of the solvent. The boiling point of a liquid is the temperature at which its vapour pressure equals the external pressure allowing the change of state. Considering a standard, mantelheated, batch reaction, once the solvent boiling point is

\footnotetext{
*Address correspondence to this author at the Department of Pharmaceutical Sciences, Group of Catalysis and Green Chemistry - University of Perugia, Via del Liceo 1 - 06100 Perugia, Italy; Tel/Fax: 39 3921289302; E-mail: sancineto.luca@gmail.com
}

reached, all of the energy that is administered to the system is dispersed through the evaporating molecules. By increasing the external pressure, the vapour pressure of the solvent increases as well, and thus its boiling point. As the boiling point is exceeded, the reaction rate increases according to the physical dependence given by Arrhenius equation which defines that every $10^{\circ} \mathrm{C}$ of temperature increment results in approximately double reaction rate [9]. In addition, the pressure increment reduces reaction volume, hence the concentration of reagents and their collision frequency are increased. When the desired reaction is accelerated, the competing decompositions of reagents could be also minimized enabling cleaner reactions profiles.

Among the devices developed for high-pressure chemistry, Q-tube ${ }^{\circledR}$ (hereafter referred to as Q-tube) provided by Q Labtech is surely the simplest and cheapest alternative (illustrations together with exhaustive technical details can be found at the website: http://www.qlabtech.com). Q-tube is a patented, safe pressure reactor, featuring a pressure release and reseal system that prevents explosions due to overpressures. It is considered a viable alternative to expensive MW synthesizers, but at the same time, it is also suitable for those solvents that are MW transparent.

In this mini review, the utility of Q-tube in multicomponent reactions will be discussed, then examples in which it enabled the synthesis of heterocyclic systems will be given prior to deal with some catalytic approaches. Finally, recent reports in which this technology has been applied for the manufacturing of biofuels will be provided. 


\section{MULTICOMPONENT REACTIONS}

Multicomponent Reactions (MCRs) are convergent synthetic approaches whereby three or more starting materials react to form a final product that contains all or most of the atoms of the initial products $[10,11]$. In a MCR, the product arises from a series of simple organic reactions and is the thermodynamically stable combination in a series of possible intermediate equilibriums. The success of MCRs strongly depends on the minimization of the side products and this can be achieved by modulating the reaction conditions. With this in mind, Procopio and co-workers revisited the Biginelli reaction for the synthesis of pyrimidines using nonconventional technologies such as MW and Q-tube (Scheme 1) [12].
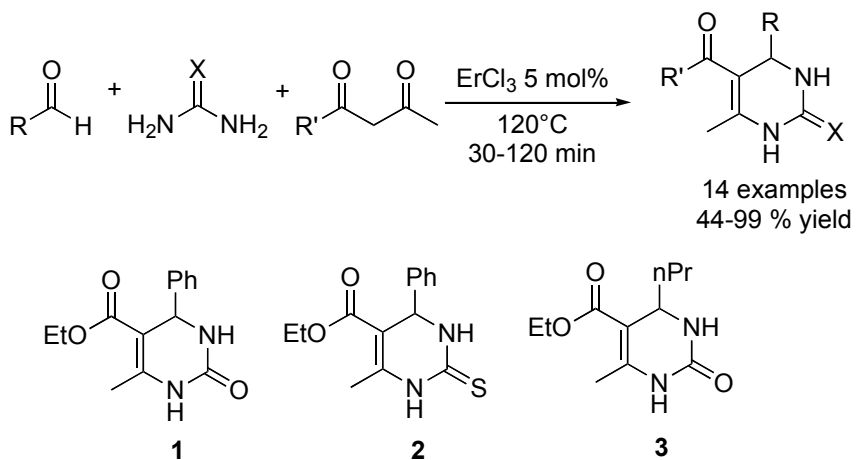<smiles>CCOC(=O)C1=C(C)NC(=S)NC1c1ccccc1</smiles><smiles>CCOC(=O)C1=C(C)NC(=O)NC1C(C)C</smiles>

(Scheme 1). The Biginelli reaction.

The authors prepared a small set of Monastrol derivatives, which is a lead compound in the anticancer research field, by reacting variously functionalized dicarbonyl compounds, ureas and aldehydes at $120^{\circ} \mathrm{C}$ in solvent free conditions in the presence of catalytic amount of the Lewis acid $\mathrm{ErCl}_{3}$. All the reactions were carried out in both Q-tube and under MW irradiation. Surprisingly, Q-tube emerged not only as a valid alternative technique but also it provided a cleaner reaction profile in a shorter reaction time. Indeed, to get complete conversion the $\mathrm{MW}$-assisted synthesis required 90 minutes while in the Q-tube the reactions needed just 30 minutes to be concluded. A head to head comparison of the reactions for the preparation of compound $\mathbf{1 - 3}$, is given in Table 1 .

Table 1. Conversion and yields for compounds $1-3 .^{a}$

\begin{tabular}{|c|c|c|c|c|}
\hline & \multicolumn{2}{|c|}{ Q-tube } & \multicolumn{2}{c|}{ MW Reactor } \\
\hline & Conversion & Yield & Conversion & Yield \\
\hline \hline $\mathbf{1}$ & 100 & 92 & 90 & 50 \\
\hline $\mathbf{2}$ & 100 & 90 & 90 & 45 \\
\hline $\mathbf{3}$ & 75 & 64 & $47(75)^{\mathrm{b}}$ & $5(54)^{\mathrm{b}}$ \\
\hline
\end{tabular}

${ }^{\mathrm{a}}$ All the reactions were conducted at $120^{\circ} \mathrm{C}$ in $30 \mathrm{~min} ;{ }^{\mathrm{b}}$ carried out in $90 \mathrm{~min}$.

As evident from (Table 1), both methods worked well but the Q-tube apparatus afforded higher yields, this is particularly evident for the synthesis of compound $\mathbf{3}$ obtained by comparable conversion and yields with MW but after 90 minutes of reaction time.

Starting from the assumption that the high pressure enhances reactions with negative activation volumes such as the [4+2] cycloadditions [13], Elnagdi et al. reported the Qtube promoted synthesis of benzo[c]chromen-6-one and phenanthridin-6(5H)-one derivatives by reacting at $120{ }^{\circ} \mathrm{C}$, ethylcyanoacetate with alkynes and acetophenones bearing amino or hydroxyl substituents in the ortho position. Under neat conditions, they obtained the desired compounds in moderate to good yields in just 25-30 minutes (Scheme 2) [14].

In order to test the versatility of the developed protocol, they replaced the alkyne with naphthoquinone preparing the pentacyclic compounds 6 in good yields.

Very recently, the same research group developed a Qtube assisted procedure to synthesize highly substituted pyridazino $[5,4,3-d e][1,6]$ naphthyridines in moderate to good yields (Scheme 3) [15]. The reactions have been carried out in dioxane at $150{ }^{\circ} \mathrm{C}$ in 60 minutes. The reaction temperature is far above the solvent boiling point $\left(101^{\circ} \mathrm{C}\right)$. An interesting aspect is that in this example Q-tube worked as an enabling technology, indeed the same reactions carried out under standard conditions did not gave the target compounds but other molecules derived from different reaction pathways.

\section{SYNTHESIS OF HETEROCYCLES}

The development of efficient and practical synthetic pathways for the construction of a variety of aromatic and heteroaromatic ring systems is one of the major goals in organic chemistry and the implementation of greener procedures is highly demanded. In keeping with this, Jha et al. turned their attention to elaborate a new and versatile procedure for the preparation of polycyclic heteroaromatic compounds which was also employed for the synthesis of thiopyrano [2,3-b:6,5-b'] diindoles (Scheme 4).

The synthetic method involves the reaction between variously functionalized indoles bearing an aldehydic group at the $\mathrm{C}-3$ position and indoline-2-thione in the presence of ethylene diamine diacetyl (EDDA) in acetonitrile at $100{ }^{\circ} \mathrm{C}$ (20 ${ }^{\circ} \mathrm{C}$ above its boiling point). Interestingly, all of the reactions were found to occur instantaneously, indeed just 30 seconds were required for the complete conversion of starting indoles into the fused compounds. The use of Q-tube was found not to be an absolute requirement for the formation of the products $\mathbf{8}$. These derivatives could be obtained under standard conditions in refluxing $\mathrm{CH}_{3} \mathrm{CN}$ but the reaction time was found to be longer (30 minutes) [16].

Indanones and related compounds are important bioactive molecules and for this reason they are considered synthetic targets by the organic chemistry community. These compounds have exhibited biological activities against cancer cells and Alzheimer's disease. The most famous drug which bears an indanone moiety is indeed donepezil hydrochloride, which has been approved by the United States Food and Drug Administration for the treatment of mild-moderate Alzheimer's disease [17]. Indanones are commonly obtained via intramolecular Friedel-Crafts acylation of 3-arylpropionic 


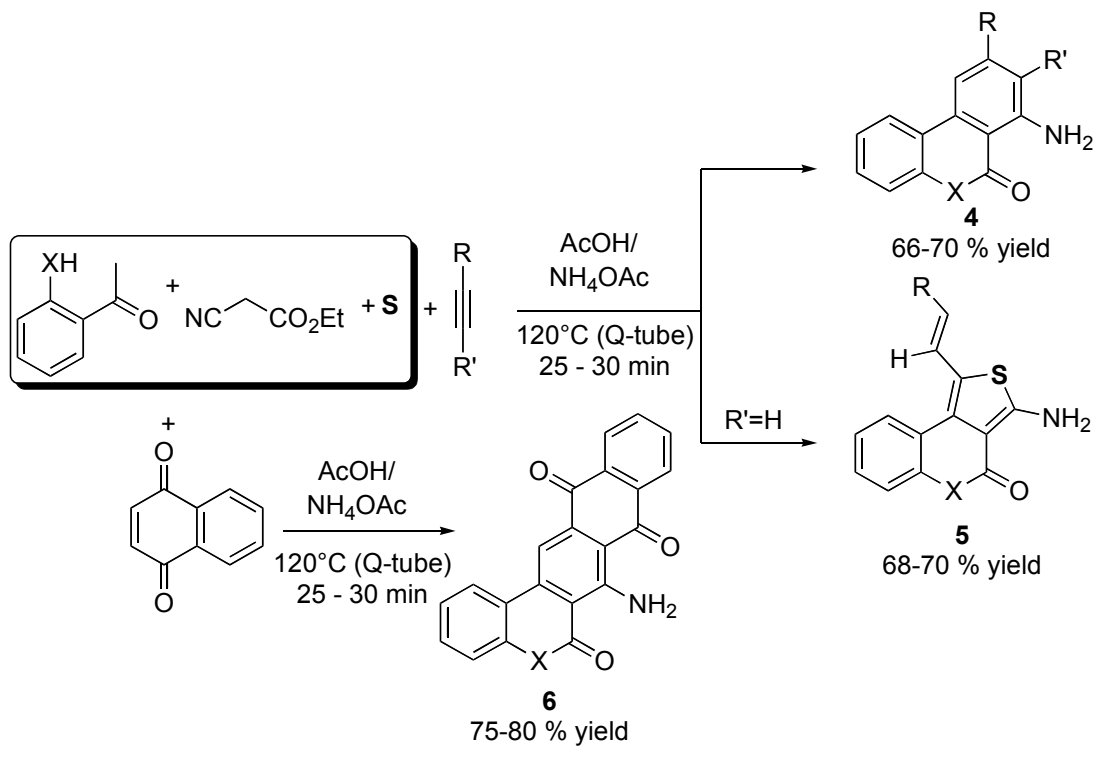

(Scheme 2). Four component reaction toward heterocyclic scaffolds.<smiles>[R]CC(=O)/C=N/N[Ga]</smiles>

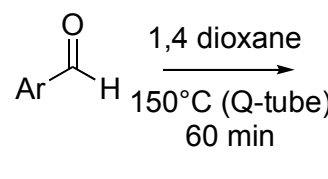<smiles>[R]c1c([Al])nc2c(C#N)c(N)nc3c2c1C=NN3[Al]</smiles>

(Scheme 3). Three component reaction to pyridazino[5,4,3-de][1,6]naphthyridines.

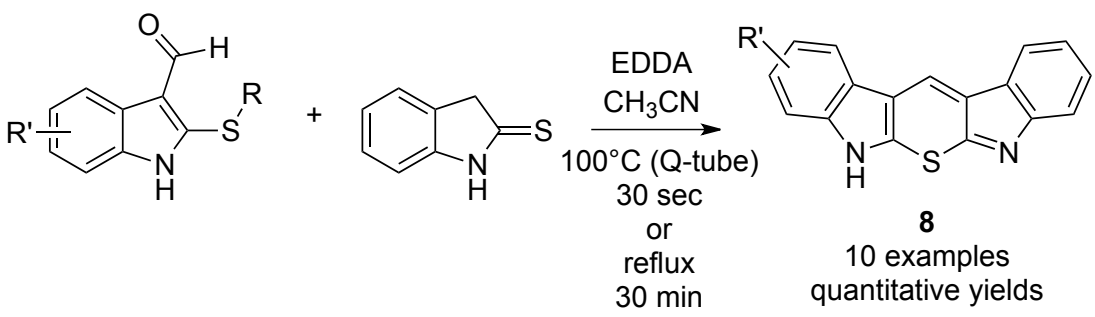

(Scheme 4). Synthesis of pentacyclic compounds.

acids using harsh reaction conditions which usually employ strong acids as solvents. In order to develop a greener procedure Procopio and co-workers performed the Friedel-Crafts reaction in nonconventional conditions (Scheme 5) [18].

The intramolecular acylation was performed in the presence of triflic acid in DCM under MW irradiation, highintensity ultrasound (US) [19] and high-pressure conditions using Q-tube. In Table 2, some results are collected to enable a head to head comparison of the three methods.

The MW-assisted and Q-tube assisted procedures allowed the complete conversion of the starting substrates into the final products in shorter reaction times (60-180 minutes) than the US-activated approaches (150-1200 minutes). On the other hand, US-assistance allowed the reactions to be conducted at a lower temperature $\left(40{ }^{\circ} \mathrm{C}\right.$ vs $110^{\circ} \mathrm{C}$ of $\mathrm{MW}$ and Q-tube) and afforded higher yields. In most of the cases, the Q-tube technology gave the same results as the MWassisted protocol in term of conversion but with cleaner reaction profiles.

An interesting comparison between conventional heating and nonconventional conditions was very recently performed by AlMarzouq et al. [20]. The reaction between a diazene and some electron poor double and triple bonds in absolute ethanol gave the target structures 11-14 depicted in Scheme 6, this was used as model to compare the four different methodologies (Table 3). Unfortunately, the authors performed the MW-assisted reactions using a domestic instrument instead of a veritable MW synthesizer. However the outcomes clearly indicated that the best results in term of yield were obtained by using Q-tube, which afforded the 
products in moderate to good yields. US assisted synthesis worked well for all of the substrates giving yields always above $70 \%$. From the reaction time point of view, MWassisted synthesis proved to be the method of choice to get quantitative conversions in few minutes (1-4 minutes). Comparable results were obtained with Q-tube while the time required for US and conventional heating was of hours. Overall, among the 4 methods, Q-tube surely emerged as the best in class for the quick and efficient synthesis of these heterocyclic compounds.<smiles>[R]c1cc(CCC(=O)O)c([R])c([R])c1[R]</smiles><smiles>CC(C)CC(C)C</smiles><smiles>[R]Cc1c([R])c([R])c2c(c1[R])CCC2=O</smiles>

14 examples<smiles>COc1ccc2c(c1)C(=O)CC2</smiles>

9<smiles>O=C1CCc2c(Br)cccc21</smiles>

10
(Scheme 5). Intramolecular Friedel-Crafts acylation to indanones.

\section{CATALYTIC APPROACHES}

Very few examples of catalytic approaches coupled with Q-tube device have been reported in literature. Porcheddu [21] and co-workers in 2013 developed a two-step procedure for the synthesis of indoles, that are considered privileged scaffolds from a medicinal chemistry point of view $[22,23]$. As shown in Scheme 7, the $\mathrm{Pd} / \mathrm{C}$-catalysed reaction of primary amines and hydrazines, in the presence of crotonitrile as hydrogen acceptor, in toluene at $150{ }^{\circ} \mathrm{C}$ gave the corresponding hydrazones 15 even after $12 \mathrm{~h}$.

In this first step, several palladium catalysts were tested and the best results were obtained with Pd on carbon, which was also recycled and reused for five consecutive cycles without reduction of catalytic efficacy. Beside toluene, the same reaction was also carried out in greener solvents such as water and under neat conditions with comparable yields of compounds 16. Once prepared, the whole set of hydrazones was converted into indoles through the Fisher indolization reaction [24] catalysed by $\mathrm{ZnCl}_{2}$ using 2-methyl-2-butanol (tert-amyl alcohol, TAA) as solvent. In one example the authors proved a single step approach by adding both catalyst together with the primary amine and the hydrazine without isolating the hydrazone 16. They eventually obtained the target indoles but in lower yields thus they preferred the two steps procedure for the library construction.

A p-toluenesulfonic acid (p-TSA) - catalysed strategy to modify aldehyde- containing indoles was developed by Blanchard et al. in 2013. In their study a comparative investigation was performed by carrying out the optimization of the reaction conditions not only in Q-tube but also in conventional heating and under MW irradiation (Scheme 8) [25].

Using catalytic amount of p-TSA and in presence of alcohols, the formyl indoles were easily converted into the corresponding enol ethers. Among the tested procedures, Qtube emerged as the best system because allowed quantitative yields to be obtained in reasonable time where standard reflux and $\mathrm{MW}$-assisted synthesis required longer reaction times.

In the medicinal chemistry research field $\mathrm{Pd}(\mathrm{OAc})_{2}$ catalysed coupling reactions in Q-tube were recently reported $[26,27]$. In one example, the use of such system was required, as the author stated, to reduce the reaction time [27].

\section{BIOFUELS DEVELOPMENT}

An interesting application of the Q-tube technology is in the biomass processing for the manufacturing of biofuels. Given the current energy crisis and the global warming there is an urgent need to exploit alternative and renewable energy sources, such as biomass [28, 29]. Therefore, new methods for biomass processing are highly demanded.

In 2017, Martinez-Palou used Q-tube in combination with ionic liquids (ILs) to promote a easier depolymerisation of the lignocellulosic biomass derived from Taiwan grass [30]. After a design of experiments-guided process optimization, the Q-tube/ILs was discovered as a synergistic couple, very efficient for the biomass pre-treatment, which was completed in 1 hour with high yields of reducing and total sugars after enzymatic hydrolysis. The authors initially screened a series of 24 ionic liquids, then with the best one an experiment was performed with conventional heating to prove the Q-tube effect. As expected, an improvement of the whole process, in terms of total free sugars, was observed as a result of pressure increment, which may allow easier depolymerisation of lignin-derived cellulose.

Recently, a new route for producing drop-in diesel or jet fuels, which combines the use of furfural, obtained by the catalytic dehydration of lignocellulosic pentose sugars, and

Table 2. Comparison between MW, US and Q-tube activated synthesis of indanones.

\begin{tabular}{|c|c|c|c|c|c|c|c|c|c|}
\hline & \multicolumn{3}{|c|}{ US } & \multicolumn{3}{c|}{ MW Reactor } & \multicolumn{3}{c|}{ Q-tube } \\
\hline & $\begin{array}{c}\text { Time } \\
(\mathbf{m i n})\end{array}$ & $\begin{array}{c}\text { T } \\
\left({ }^{\circ} \mathbf{C}\right)\end{array}$ & $\begin{array}{c}\text { Yield } \\
(\%)\end{array}$ & $\begin{array}{c}\text { Time } \\
(\mathbf{m i n})\end{array}$ & $\begin{array}{c}\text { T } \\
\left({ }^{\circ} \mathbf{C}\right)\end{array}$ & $\begin{array}{c}\text { Yield } \\
(\%)\end{array}$ & $\begin{array}{c}\text { Time } \\
(\mathbf{m i n})\end{array}$ & $\begin{array}{c}\text { T } \\
\left({ }^{\circ} \mathbf{C}\right)\end{array}$ & $\begin{array}{c}\text { Yield } \\
(\%)\end{array}$ \\
\hline \hline $\mathbf{9}$ & 150 & 40 & 99 & 60 & 110 & 99 & 60 & 110 & 99 \\
\hline $\mathbf{1 0}$ & 1200 & 40 & 90 & 180 & 110 & 48 & 180 & 110 & 43 \\
\hline
\end{tabular}




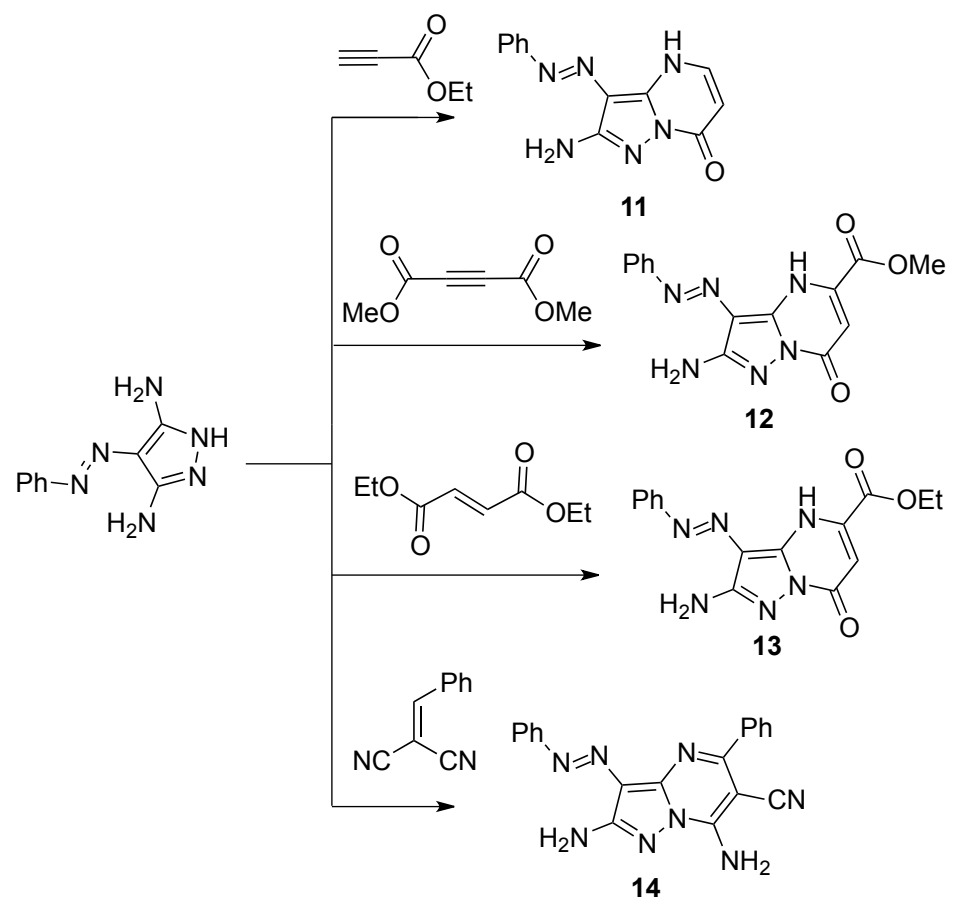

(Scheme 6). Synthesis of pyrazolopyrimidinones 11-13 and pyrazolopyrimidines 14.

Table 3. Comparison between MW, US and Q-tube activated synthesis of indanones.

\begin{tabular}{|c|c|c|c|c|c|c|c|c|}
\hline & \multicolumn{2}{|c|}{ Conventional Heating ${ }^{a}$} & \multicolumn{2}{|c|}{$\mathbf{U} \mathbf{S}^{\mathbf{b}}$} & \multicolumn{2}{|c|}{ MW Reactor ${ }^{\mathrm{c}}$} & \multicolumn{2}{|c|}{ Q-tube $^{d}$} \\
\hline & $\begin{array}{c}\text { Time } \\
\text { (hours) }\end{array}$ & $\begin{array}{c}\text { Yield } \\
(\%)\end{array}$ & $\begin{array}{c}\text { Time } \\
\text { (hours) }\end{array}$ & $\begin{array}{c}\text { Yield } \\
(\%)\end{array}$ & $\begin{array}{l}\text { Time } \\
(\min )\end{array}$ & $\begin{array}{c}\text { Yield } \\
(\%)\end{array}$ & $\begin{array}{l}\text { Time } \\
\text { (min) }\end{array}$ & $\begin{array}{c}\text { Yield } \\
\text { (\%) }\end{array}$ \\
\hline 11 & 6 & 85 & 3 & 82 & 1 & 60 & 5 & 90 \\
\hline 12 & 7 & 75 & 4 & 84 & 1 & 55 & 10 & 80 \\
\hline 14 & 5 & 68 & 3 & 73 & 2 & 65 & 5 & 76 \\
\hline
\end{tabular}

${ }^{\text {a }}$ The reaction has been carried out at reflux; ${ }^{\mathrm{b}} \mathrm{The}$ reaction has been carried out at $80^{\circ} \mathrm{C} ;{ }^{\mathrm{c}} \mathrm{The}$ reaction has been carried out in neat condition; ${ }^{\mathrm{d}}$ The reaction has been carried out at $140^{\circ} \mathrm{C}$.

$$
\text { (2) examples }
$$

(Scheme 7). Two step synthesis of indoles.

alcohols produced from a variety of bio or petroleum feedstocks has been reported by Bell, Scown, Toste et al. [31]. The dehydrogenative cross-coupling reaction of furfural and alcohols was found to be catalysed by a recyclable transitionmetal-free hydrotalcite (HT) and led to high molecular weight furanyl adducts via a transfer hydrogenation-aldol condensation. The optimization studies, such as the catalyst screening along with the evaluation of the substrate scope for the dehydrogenative cross-coupling reaction (Scheme 9) of various bioalcohols and lignocellulosic furfural were performed in Q-tube at high temperature in toluene.

The highly selective cross-condensation proceeded, as suggested, via a hydride transfer from butanol to furfural, consistent with the Meerwein-Ponndorf-Verley reaction [32], followed by an aldol condensation of the resulting bu- 
tyraldehyde with a second molecule of furfural. The second step of the developed synthetic strategy to upgrade lignocellulosic furfural to high value biofuels involved the hydrogenation of adducts. The reaction was conducted in a Mini Parr reactor using $\mathrm{Pt} / \mathrm{NbOPO}_{4}$ as catalyst at elevated pressure and temperature. The hydrodeoxygenation of furanyl aldehydes 19 provided a mixture of cyclic and acyclic alkanes consisting of $\mathrm{C} 8-\mathrm{C} 19$ carbons in $75-78 \%$ total yield (Scheme 10), that can be applied as blendstocks for jet and diesel fuels.

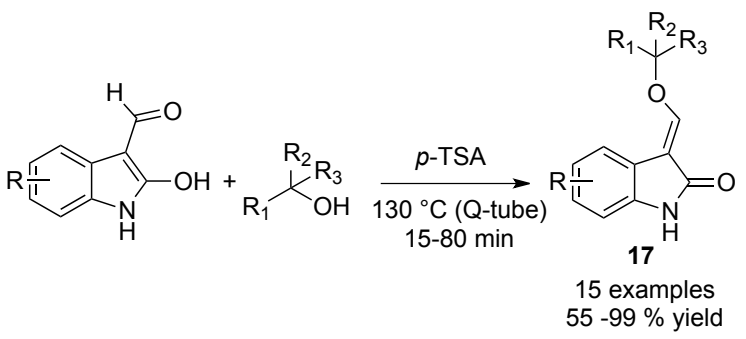

(Scheme 8). Modification of indoles.

Other biofuel solutions such as biomass derived cycloalkanes, which offer up to $81 \%$ Greenhouse Gas (GHG) reduction benefits have also been proposed by the same research group [33]. It was exemplified by the reported novel method for selectively upgrading biomass-derived alkyl methyl ketones into trimer condensates. The latter of which can then be hydrodeoxygenated in near-quantitative yields to give a new class of cycloalkane compounds for aviation fuels as well as lubricants applications. The developed strategy involves initial conversion of sugars in sugarcane-derived sucrose as well as the conversion of hemicellulose to ketones using a combination of chemical and biocatalytic processes. The self-condensation reaction of the biomass obtained ketones was first examined in order to optimize the reaction conditions and screen heterogeneous acid/base catalysts (Scheme 11, Table 4). The detailed catalyst screening for the condensation of 2-hexanone was also reported independently [34] and the calcined hydrotalcite, $\mathrm{Mg}-\mathrm{Al}-\mathrm{O}(\mathrm{Mg} / \mathrm{Al}=3)$ was found to be the most efficient heterogeneous species, which could selectively produce cyclic and aromatic trimer condensates. The reaction was conducted in a sealed Q-tube reactor at high temperature in toluene. It was demonstrated that ketones containing methyl functionality undergo selective trimerization to produce condesates of $\mathbf{2 7}$ and 28 in the presence of a base $(\mathrm{MgAlO})$ and acid $\left(\mathrm{Nb}_{2} \mathrm{O}_{5}\right)$ catalysts, whereas ketones with longer hydrocarbon chains at both ends condense to form mostly dimers (26). Furthermore, it was found that the selective formation of $\mathbf{2 7}$ and $\mathbf{2 8}$ was dependent on the nature of the catalyst (acid/base).

The hydrodeoxygenation of condensates (26-28) was accomplished in the liquid phase at $160{ }^{\circ} \mathrm{C}$ with $3.5 \mathrm{MPa}$ of $\mathrm{H}_{2}$ using $\mathrm{Pt} / \mathrm{NbOPO}_{4}$ for $5-12 \mathrm{~h}$ to produce quantitatively cyclic and acyclic alkanes 29-31 (Scheme 12), that serve as potential jet fuels (C12-C21) and synthetic lubricants (C33+).

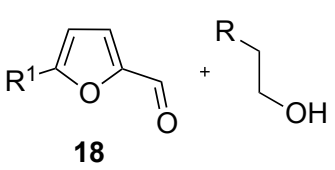

$\mathrm{R}^{1}=\mathrm{H}, \mathrm{Me} \quad \mathrm{R}=\mathrm{Alk}, \mathrm{Ar}$

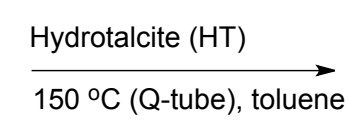

$\mathrm{HT}=\mathrm{Mg}_{6} \mathrm{Al}_{2}(\mathrm{OH})_{16} \mathrm{CO}_{3} \cdot 4 \mathrm{H}_{2} \mathrm{O}$

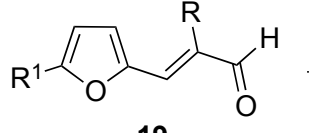

19

11 examples 48-99\%<smiles>[R]CCOC(=O)c1ccc([R])o1</smiles>

20

Selectivity of $99: 1$ for $19: 20$

(Scheme 9). Dehydrogenative cross-coupling reaction of furfural.

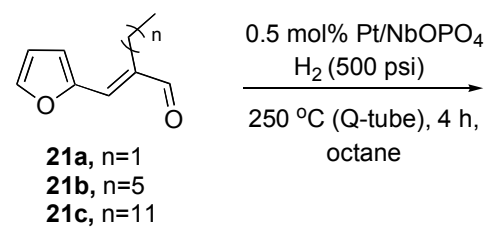

$21 b, n=5$

21c, $n=11$

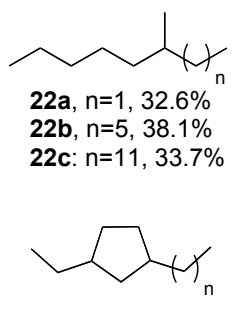

24a, $n=1,11.7 \%$

24b, $n=5,11.6 \%$

24c: $n=11,18.1 \%$
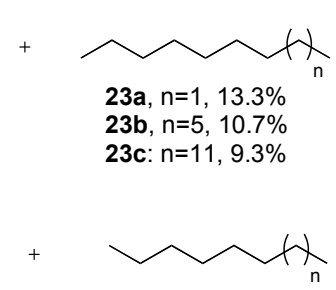

25a, $n=1,20.1 \%$

25b, $n=5,17.3 \%$

25c: $n=11,14.1 \%$

(Scheme 10). Hydrodeoxygenation of furanyl aldehydes.

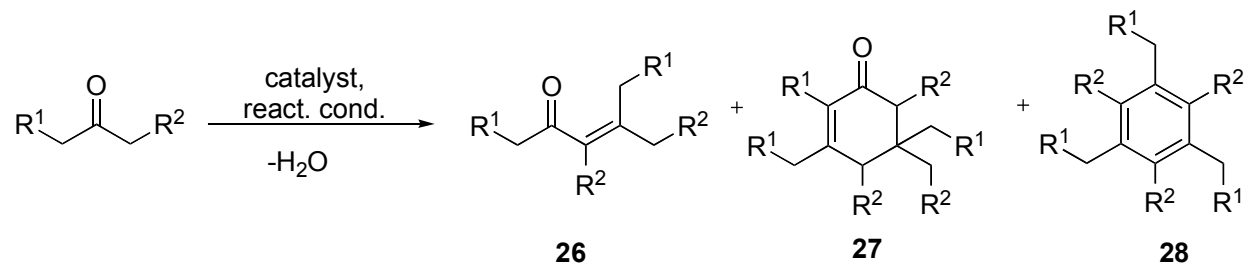

(Scheme 11). Self-condensation reaction of the biomass obtained ketones. 
Table 4. Self-condensation of ketones in the presence of solid acid/base catalysts.

\begin{tabular}{|c|c|c|c|c|c|c|c|c|c|}
\hline \multicolumn{3}{|c|}{ Ketones } & \multirow{2}{*}{ Cat. } & \multirow{2}{*}{ Temp. $\left[{ }^{\circ} \mathrm{C}\right]$} & \multirow{2}{*}{ Time $[\mathbf{h}]$} & \multirow{2}{*}{$\begin{array}{c}\text { Conv. } \\
{[\%]}\end{array}$} & \multicolumn{3}{|c|}{ Yields [\%] } \\
\hline no & $\mathbf{R}^{1}$ & $\mathbf{R}^{2}$ & & & & & 26 & 27 & 28 \\
\hline 1 & $\mathrm{Me}$ & $\mathrm{H}$ & $\mathrm{MgAlO}$ & 170 & 3 & 100 & 0 & 95 & 0 \\
\hline 2 & $\mathrm{Et} / \mathrm{Pr} / n-\mathrm{Bu}$ & $\mathrm{H}$ & $\mathrm{MgAlO}$ & 150 & 3 & 100 & 0 & $95-98$ & 0 \\
\hline $3^{\mathrm{a}}$ & $n-\operatorname{Pr}$ & $\mathrm{H}$ & $\mathrm{MgAlO}$ & 150 & 3 & 99 & 0 & 97 & 0 \\
\hline 4 & $\begin{array}{c}n \text {-Pentyl } \rightarrow n \text { - } \\
\text { Docecyl }\end{array}$ & $\mathrm{H}$ & $\mathrm{MgAlO}$ & 180 & 12 & 100 & 0 & $96-99$ & 0 \\
\hline 5 & Et & $\mathrm{H}$ & $\mathrm{Nb}_{2} \mathrm{O}_{5}$ & 180 & 6 & 99 & 1 & 8 & 73 \\
\hline 6 & $n$-Bu & $\mathrm{H}$ & $\mathrm{Nb}_{2} \mathrm{O}_{5}$ & 180 & 6 & 98 & 2 & 8 & 78 \\
\hline 7 & Et & Et & $\mathrm{Nb}_{2} \mathrm{O}_{5}$ & 180 & 20 & 86 & 73 & 0 & 0 \\
\hline 8 & $n$-Bu & Et & $\mathrm{Nb}_{2} \mathrm{O}_{5}$ & 180 & 20 & 79 & 69 & 0 & 0 \\
\hline 9 & $n$-Bu & $n$-Bu & $\mathrm{Nb}_{2} \mathrm{O}_{5}$ & 180 & 20 & 61 & 54 & 0 & 0 \\
\hline
\end{tabular}

Ketones ( $2 \mathrm{mmol})$, catalyst (200 $\mathrm{mg})$, toluene ( $3 \mathrm{ml}) ;{ }^{\mathrm{a}}$ Cyclohexane $(3 \mathrm{ml})$ instead of toluene.

26-28

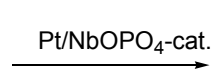<smiles>[R]CCC([R])=C(C[R])C[R]</smiles>

29<smiles>[R]CC1C([R])CC([R])C([R])(C[R])C1[R]</smiles>

30

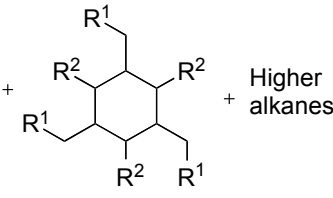

31

(Scheme 12). Reduction of the condensed products.

Another reported protocol which enables the kilogram scale production of high-value biofuel precursors from fermentation solvents consisted of the combination of the biological fermentation and chemical catalysis [35]. This twostep approach was achieved by the Acetone-Butanol-Ethanol (ABE) extractive fermentation of sugar using solventogenic strains of bacteria Clostridium acetobutylicum, followed, by the conversion of ABE mixture to long-chain ketones after a palladium-hydrotalcite (Pd-HT)-catalysed reduction. This catalytic reaction is carried out in Q-tube for $20 \mathrm{~h}$ at $250{ }^{\circ} \mathrm{C}$, providing blends of ketones via dehydrogenation-aldol condensation in excellent overall yield (up to $86 \%$ ). The more details on the experimental part along with the troubleshooting were described. The activity and recyclability of a number of catalysts in the chemical catalysis route to generate aliphatic ketones from a biomass-derived fermentation mixture (ABE or IBE) has been broadly explored in the procedures using previously reported $\mathrm{Pd} / \mathrm{C}-\mathrm{K}_{3} \mathrm{PO}_{4}$ [36] or transition metal based hydrotalcite catalysts [37].

\section{OTHERS}

Several papers have been published where the use of Qtube is not the central subject of the research but it was employed just to speed up known processes. These examples will be cited briefly because the advantages associated to this device were not discussed in the original articles. In this context, the Q-tube was used to replace halogens with amino groups on inactivated substrates in the frame of a wider study aimed to develop estrogen analogues [38]. While a series of reductive amination were performed under solvent free conditions to prepare anti-tubercular agents [39]. Q-tube was also recently used in inorganic synthesis to prepare iron and cadmium-based nanocristals [40, 41].

\section{CONCLUSION}

In conclusion, the use of Q-tube to develop HPC is a field of interest that is becoming more and more important among the green chemistry practitioners. Here, we have collected the papers deliberately focused on the use of such technology but the scale of survey is certainly not exhaustive since in many articles the use of Q-tube is hidden in the experimental details or even in supplementary files. In the field of organic chemistry research, this device has been used in the development of MCRs, synthesis of heterocycles, transition metals-catalysed processes and biofuel manufacture, as a result Q-tube can be surely considered not only a mere alternative to the expensive MW synthesizers or the cheaper version of the high-pressure reactors but also a valuable tool, which will become indispensable in every chemical laboratory in the near future. Indeed, in almost every case in which it is used and compared with conventional heating and nonconventional technologies Qtube emerged as the best alternative, affording high yields and clean reaction profiles.

\section{CONSENT FOR PUBLICATION}

Not applicable. 


\section{CONFLICT OF INTEREST}

The author declares no conflict of interest, financial or otherwise.

\section{ACKNOWLEDGEMENTS}

LS acknowledges the European Union's Horizon 2020 research and innovation programme under the Marie Skłodowska-Curie grant agreement No 665778 - POLONEZ funding programme, National Science Centre, Poland - project registration number 2016/21/P/ST5/03512. FM acknowledges consorzio CINMPIS, Bari (Consorzio Interuniversitario Nazionale di Metodologie e Processi Innovativi di Sintesi). This manuscript is part of the activities of the multi-disciplinary group "SeS redox and catalysis".

\section{REFERENCES}

[1] Sancineto, L.; Palomba, M.; Bagnoli, L.; Marini, F.; Santi, C. Advances in electrophilic organochalcogen reagents. Curr. Org. Chem., 2015, 20, 122-135.

[2] Sancineto, L.; Mangiavacchi, F.; Tidei, C.; Bagnoli, L.; Marini, F.; Gioiello, A.; Scianowski, J.; Santi, C. Selenium-catalyzed oxacyclization of alkenoic acids and alkenols. Asian J. Org. Chem., 2017, 6(8), 988-992.

[3] Monti, B.; Santi, C.; Bagnoli, L.; Marini, F.; Sancineto, L. Zinc halcogenolates as green reagents. Curr. Green Chem., 2016, 3, 6875 .

[4] Isaacs, N.S. Liquid Phase High Pressure Chemistry; John Wiley \& Sons, Inc.: Chichester, 1981

[5] Zhang, Y.; Mosey, N.J. High pressure chemistry of thioaldehydes: A first-principles molecular dynamics study. J. Chem. Phys., 2016, $145,194506 / 1-194506 / 11$.

[6] Im, J.; Yim, N.; Kim, J.; Vogt, T.; Lee, Y. High-pressure chemistry of a zeolitic imidazolate framework compound in the presence of different fluids. J. Am. Chem. Soc., 2016, 138, 11477-11480.

[7] Horvath-Bordon, E.; Riedel, R.; Zerr, A.; McMillan, P.F.; Auffermann, G.; Prots, Y.; Bronger, W.; Kniep, R.; Kroll, P. Highpressure chemistry of nitride-based materials. Chem. Soc. Rev. 2006, 35, 987-1014.

[8] Harwood, L. M. High pressure chemistry. Synthetic, mechanistic and supercritical applications. Edited by Rudi van Eldik and FrankGerrit Klarner. Angew. Chemie Int. Ed., 2003, 42, 4852-4852.

[9] Arrhenius equation. In IUPAC Compendium of Chemical Terminology; IUPAC: Research Triagle Park, NC.

[10] Melo, R.L.; Silva, A.W. Ionic liquid in multicomponent reactions: A brief review. Curr. Green Chem., 2016, 3, 120-132.

[11] Chaudhary, A.; Saluja, P.; Khurana, J.M. Recent advances in the application of meldrum's acid in multicomponent reactions. Curr. Green Chem., 2017, 3, 328-345.

[12] Oliverio, M.; Costanzo, P.; Nardi, M.; Rivalta, I.; Procopio, A. Facile ecofriendly synthesis of monastrol and its structural isomers via biginelli reaction. ACS Sustain. Chem. Eng., 2014, 2, 12281233.

[13] Kiselev, V.D.; Kornilov, D.A.; Lekomtseva, I.I.; Konovalov, A.I. Reactivity of 4-phenyl-1,2,4-triazoline-3,5-dione and diethylazocarboxylate in [4+2]-cycloaddition and ene reactions: Solvent, temperature, and high-pressure influence on the reaction Rate. Int. $J$. Chem. Kinet., 2015, 47, 289-301.

[14] Alzaydi, K.M.; Abojabal, N.S.; Elnagdi, M.H. Multicomponent reactions in Q-tubes: One-pot synthesis of benzo[c]chromen-6-one and phenanthridin- $6(5 \mathrm{H})$-one derivatives in a four-component reaction. Tetrahedron Lett., 2016, 57, 3596-3599.

[15] Sadek, K.U.; Selim, M.A.; Alnajjar, A.-A.; Atallah, M.; Elnagdi, M.H. Multicomponent reactions under increased pressure: on the reaction of arylhydrazonals, aromatic aldehydes and malononitrile in Q-Tube. Eur. J. Chem., 2016, 7, 468-472.

[16] Jha, M.; Edmunds, M.; Lund, K.; Ryan, A. A new route to the versatile synthesis of thiopyrano[2,3-b:6,5-b']diindoles via 2(alkylthio)-indole-3-carbaldehydes. Tetrahedron Lett., 2014, 55, 5691-5694.
[17] Sugimoto, H. Structure-activity relationships of acetylcholinesterase inhibitors: Donepezil hydrochloride for the treatment of Alzheimer's Disease. Pure Appl. Chem., 1999, 71, 2031-2037.

[18] Oliverio, M.; Nardi, M.; Costanzo, P.; Cariati, L.; Cravotto, G.; Giofre, S.; Procopio, A. Non-conventional methodologies in the synthesis of 1-indanones. Molecules, 2014, 19, 5599-5610.

[19] Puri, S.; Kaur, B.; Parmar, A.; Kumar, H. Applications of ultrasound in organic synthesis - A green approach. Curr. Org. Chem., 2013, 17, 1790-1828.

[20] AlMarzouq, D.S.; Zaky, O.S.; AlNajjar, A.A.; Sadek, K.U. Pressure as effective green technology for synthesis of polyfunctionally substituted heteroaromatics: Synthesis of a variety of pyrazolo[1,5-a]pyrimidines. Eur. J. Chem., 2016, 7, 347-351.

[21] Taddei, M.; Mura, M.G.; Rajam?ki, S.; Luca, L. De; Porcheddu, A. Palladium-catalysed dehydrogenative generation of imines from amines. A nature-inspired route to indoles via cross-couplings of amines with arylhydrazines. Adv. Synth. Catal., 2013, 355, 30023013.

[22] Ranasinghe, N.; Jones, G.B. Flow and microwave assisted synthesis of medicinally relevant indoles. Curr. Green Chem., 2015, 2, 66-76.

[23] Palomba, M.; Rossi, L.; Sancineto, L.; Tramontano, E.; Corona, A.; Bagnoli, L.; Santi, C.; Pannecouque, C.; Tabarrini, O.; Marini, F. A new vinyl selenone-based domino approach to spirocyclopropyl oxindoles endowed with anti-HIV RT activity. Org. Biomol. Chem., 2016, 14, 2015-2024.

[24] Inman, M.; Moody, C.J. Indole synthesis-something old, something new. Chem. Sci., 2013, 4, 29-41.

[25] Blanchard, D.; Cameron, T.S.; Jha, M. Bronsted acid-catalyzed rapid enol-ether formation of 2-hydroxyindole-3-carboxaldehydes. Mol. Divers., 2013, 17, 827-834.

[26] Magee, T.V.; Brown, M.F.; Starr, J.T.; Ackley, D.C.; Abramite, J.A.; Aubrecht, J.; Butler, A.; Crandon, J.L.; Dib-Hajj, F.; Flanagan, M.E.; Granskog, K.; Hardink, J.R.; Huband, M.D.; Irvine, R.; Kuhn, M.; Leach, K.L.; Li, B.; Lin, J.; Luke, D.R.; MacVane, S.H.; Miller, A.A.; McCurdy, S.; McKim, J.M.; Nicolau, D.P.; Nguyen, T.-T.; Noe, M.C.; O'Donnel, J.P.; Seibel, S.B.; Shen, Y.; Stepan, A.F.; Tomaras, A.P.; Wilga, P.C.; Zhang, L.; Xu, J.; Chen, J.M. Discovery of dap-3 polymyxin analogues for the treatment of multidrug-resistant gram-negative nosocomial infections. J. Med. Chem., 2013, 56, 5079-5093.

[27] Tomassoli, I.; Gündisch, D. The twin drug approach for novel nicotinic acetylcholine receptor ligands. Bioorg. Med. Chem., 2015, 23, 4375-4389.

[28] Luque, R. Catalytic biomass processing: Prospects in future biorefineries. Curr. Green Chem., 2015, 2, 90-95.

[29] Corma, A.; Iborra, S.; Velty, A. Chemical routes for the transformation of biomass into chemicals. Chem. Rev., 2007, 107, 2411-2502.

[30] Merino, O.; Almazan, V.; Martinez-Palou, R.; Aburto, J. Screening of ionic liquids for pretreatment of taiwan grass in Q-tube minireactors for improving bioethanol production. Waste Biomass Valorization, 2017, 8, 733-742.

[31] Sreekumar, S.; Balakrishnan, M.; Goulas, K.; Gunbas, G.; Gokhale, A.A.; Louie, L.; Grippo, A.; Scown, C.D.; Bell, A.T.; Toste, F.D. Upgrading lignocellulosic products to drop-in biofuels via dehydrogenative cross-coupling and hydrodeoxygenation sequence. Chem. Sus. Chem., 2015, 8, 2609-2614.

[32] Lee, J.; Ryu, T.; Park, S.; Lee, P.H. Indium tri(isopropoxide)catalyzed selective meerwein-ponndorf-verley reduction of aliphatic and aromatic aldehydes. J. Org. Chem., 2012, 77, 48214825 .

[33] Balakrishnan, M.; Sacia, E.R.; Sreekumar, S.; Gunbas, G.; Gokhale, A.A.; Scown, C.D.; Toste, F.D.; Bell, A.T. Novel pathways for fuels and lubricants from biomass optimized using life-cycle greenhouse gas assessment. Proc. Natl. Acad. Sci., 2015, 112, 7645-7649.

[34] Sacia, E.R.; Balakrishnan, M.; Deaner, M.H.; Goulas, K.A.; Toste, F.D.; Bell, A.T. Highly selective condensation of biomass-derived methyl ketones as a source of aviation fuel. Chem. Sus. Chem., 2015, 8, 1726-1736.

[35] Sreekumar, S.; Baer, Z.C.; Pazhamalai, A.; Gunbas, G.; Grippo, A.; Blanch, H.W.; Clark, D.S.; Toste, F.D. Production of an acetonebutanol-ethanol mixture from clostridium acetobutylicum and its conversion to high-value biofuels. Nat. Protoc., 2015, 10, 528-537. 
[36] Anbarasan, P.; Baer, Z.C.; Sreekumar, S.; Gross, E.; Binder, J.B.; Blanch, H.W.; Clark, D.S.; Toste, F.D. Integration of chemical catalysis with extractive fermentation to produce fuels. Nature, 2012, 491, 235-239.

[37] Sreekumar, S.; Baer, Z.C.; Gross, E.; Padmanaban, S.; Goulas, K.; Gunbas, G.; Alayoglu, S.; Blanch, H.W.; Clark, D.S.; Toste, F.D. Chemocatalytic upgrading of tailored fermentation products toward biodiesel. Chem. Sus. Chem., 2014, 7, 2445-2448.

[38] Abdelkhalik, A.M.; Paul, N.K.; Jha, A. Concise synthesis of 12amethyl-11-aryl-1,2-dihydrobenzo[f]pyrrolo[1,2-a]quinolin-

3(12aH)-ones as racemic 14-azaestrogen analogs. Steroids, 2015, $98,107-113$
[39] Shen, L.; M Maddox, M.; Adhikari, S.; Bruhn, D.F.; Kumar, M.; Lee, R.E.; Hurdle, J.G.; Lee, R.E.; Sun, D. Syntheses and evaluation of macrocyclic engelhardione analogs as antitubercular and antibacterial agents. J. Antibiot., (Tokyo). 2013, 66, 319-325.

[40] Alshehri, S.M.; Aldalbahi, A.; Ahamad, T.; Alhokbany, N Synthesis and characterization of mackinawite nanocrystals (FeS m) and their application in recovery of aqueous $\mathrm{Hg}$ (II) solution. Desalin. Water Treat., 2016, 57, 6594-6603.

[41] Ahamad, T.; Alshehri, S.M. Synthesis of CdS nanocrystals using polymer metal complex as a single source precursor and their physicochemical properties. Nano Hybrids, 2012, 1, 45-56. 